TITLE:

\title{
Mechanism of water adsorption capacity change of bamboo by heating
}

AUTHOR(S):

Ohmae, Yoshimi; Saito, Yukie; Inoue, Masafumi; Nakano, Takato

\section{CITATION:}

Ohmae, Yoshimi ... [et al]. Mechanism of water adsorption capacity change of bamboo by heating. European Journal of Wood and Wood Products 2008, 67(1): 13-18

\section{ISSUE DATE:}

2008-11

URL:

http://hdl.handle.net/2433/141953

\section{RIGHT:}

The final publication is available at www.springerlink.com; この論文は 出版社版でありません。引用の際には出版社版をご確認ご利用くださ $\omega_{\circ}$; This is not the published version. Please cite only the published version. 
Mechanism of water adsorption capacity change of bamboo by heating

Yoshimi Ohmae $^{1}$, Yukie Saito ${ }^{1}$, Masafumi Inoue ${ }^{2}$ and Takato Nakano ${ }^{3 *}$

1: Graduate School of Agriculture and Life Sciences, The University of Tokyo, Bunkyou-

ku Yayoi 1-1-1, Tokyo, 113-8657.

2: Asian Natural Environmental Science Center, The University of Tokyo, Bunkyou-ku Y

ayoi 1-1-1, Tokyo, 113-8657.

3: Laboratory of Biomaterials Design, Division of Forest and Biomaterials Science, Grad

uate School of Agriculture, Kyoto University, Kita-Shirakawa, Kyoto, 606-8502 Japan.

* Corresponding Author. phone: +81-75-753-9234. fax: +81-75-753-9234.

E-mail address: tnakano@kais.kyoto-u.ac.jp (T. Nakano). 


\section{Abstract}

The water adsorption capacity of mousouchiku bamboo (Phyllostachys pubescens)

heated at $200^{\circ} \mathrm{C}$ in air for various times were examined. The samples were subsequently placed

in various humidity at $20^{\circ} \mathrm{C}$, to obtain relevant isotherms. These were analyzed using Hailwood and Horrobin theory, derived for hydrophilic macromolecules, and Dubinin and Radushkevich theory, previously used to describe the behavior of microporous carbons. The results show that the water adsorption capacities of the samples changed after heating for 2 to $5 \mathrm{hr}$ and imply that over this time the number of hydroxyl groups decreased markedly while the number of micropores formed increased.

Keywords: Bamboo, heating, Water, Adsorption, Hailwood - Horrobin Theory, Dubinin -

\section{Rudshkevich Theory}




\section{Introduction}

Bamboo is a resource that grows rapidly and abundantly. It is one of the more useful

natural resources. Although bamboo has been used extensively for making handcrafted articles,

it has not been widely exploited by industry. Today, most bamboo stands are destroyed or

ignored and an effective end-use for bamboo should be sought given its contribution to the

forest biomass.

Heat treatment is an effective means of processing bamboo. Numerous studies have

shown that heat-dried bamboo absorbs a variety of substances (Abe et al. 1996a, 1996b, 2001a,

2001b; Fujiwara. 2003a). One recent investigation demonstrated its ability to condition the

humidity of a room (Fujiwara. 2003b). However, the full adsorption capacity of bamboo is

unknown and an investigation of how these changes with heating could provide information

that allows the biomass of bamboo to be exploited.

Therefore, this study considers the adsorption capacity of bamboo samples heated at a

fixed temperature of $200^{\circ} \mathrm{C}$ for different times. The results are interpreted using different

theories to provide a mechanism that accounts for the change in the adsorption capacity of

bamboo with heating time. 


\section{Experiments}

Bamboo samples were taken from a 6-year-old mousouchiku (Phyllostachys

pubescens) culm harvested on October 2004, in Shimane Prefecture in Japan. They consisted

of 27 internodes designated as No. 1 to No. 27 from the bottom to the top of the culm. The

centers of internodes No. 14 and 15 were used to provide block samples with rectangular

dimensions of $20 \times 5 \times 5(\mathrm{~L} \times \mathrm{R} \times \mathrm{T})(\mathrm{mm})$.

The samples were dried at $105^{\circ} \mathrm{C}$ for $24 \mathrm{hr}$ before the heat treatment and then heated at

$200^{\circ} \mathrm{C}$ for 0 (untreated control sample), $1,2,3,5,20,48,72,120,240$, and $360 \mathrm{hr}$. The heating

times were determined to allow the 11 data points to be plotted at nearly regular intervals on a

logarithmic scale (expressed as the natural logarithm the times are $0,0.69,1.10,1.61,3.00,3.88$,

$4.28,4.79,5.48$, and 5.89, respectively). The weight loss due to heat treatment was estimated

relative to the weight of the untreated sample.

Each sample was subsequently conditioned at $20^{\circ} \mathrm{C}$ for 3 weeks to determine the extent

of moisture adsorption, by placing samples in sealed containers conditioned by ten different

saturated solutions: $\mathrm{LiCl}(11 \% \mathrm{RH}), \mathrm{CH}_{3} \mathrm{COOK}(22 \% \mathrm{RH}), \mathrm{MgCl}_{2}(33 \% \mathrm{RH}), \mathrm{K}_{2} \mathrm{CO}_{3}(43 \%$

$\mathrm{RH}), \mathrm{LiNO}_{3}(47 \% \mathrm{RH}), \mathrm{Mg}\left(\mathrm{NO}_{3}\right)_{2}(53 \% \mathrm{RH}), \mathrm{NaBr}(57 \% \mathrm{RH}), \mathrm{NH}_{4} \mathrm{NO}_{3}(62 \% \mathrm{RH}), \mathrm{SrCl}_{3}$

(71\% RH), $\mathrm{NaCl}(75 \% \mathrm{RH}),\left(\mathrm{NH}_{4}\right)_{2} \mathrm{SO}_{4}(80 \% \mathrm{RH}), \mathrm{KCl}(84 \% \mathrm{RH}), \mathrm{BaCl}_{2}(88 \% \mathrm{RH}), \mathrm{KNO}_{3}$ 
$(92 \% \mathrm{RH}), \mathrm{Pb}\left(\mathrm{NO}_{3}\right)_{2}(95 \% \mathrm{RH})$, and $\mathrm{K}_{2} \mathrm{SO}_{4}(97 \% \mathrm{RH})$. The results were analyzed in terms of

Hailwood and Horrobin theory (Hailwood, Horrobin. 1946) and Dubinin and Radushkevich theory (Dubinin. 1960, 1965).

\section{Results and Discussion}

Figure 1 shows the weight loss of the mousouchiku blocks heated at $200^{\circ} \mathrm{C}$ for 0 to 360 $\mathrm{hr}$ in air. The weights decrease rapidly for the samples heated for less than $120 \mathrm{hr}$, while the decrease was more gradual for those heated for longer than $120 \mathrm{hr}$. This same trend occurs for wood (Nakano. 2003).

The samples were then placed in sealed containers, along with saturated solutions, at $20^{\circ} \mathrm{C}$ for $21,30,60$, and 90 days. The results differed slightly for the different adsorption periods and this paper considers only the sorption results over 21 days. The isotherms are shown in Figure 2 and were sigmoidal, with the moisture content for a given relative humidity varying with heating time over a wide variety of relative humidities. The relationship between heating time and moisture content at RH 0.93 is shown in Figure 3, which demonstrates that the hygroscopicity of a heated sample decreases for up to $5 \mathrm{hr}$, and then increases thereafter. A similar trend has been reported for heated wood (Nakano. 2003). Over a fixed heating time of 2 
$\mathrm{hr}$, the hygroscopicity of a sample decreased as the heating temperature was increased to $250^{\circ} \mathrm{C}$, but increased at higher temperatures. For the same sample, the adsorption of nitrogen gas began at $250^{\circ} \mathrm{C}$ and increased with heating temperature. Fourier transform infrared (FT-IR) measurements suggest that hydroxyl groups provide adsorption sites for water and control adsorption of samples heated below $250^{\circ} \mathrm{C}$. A comparison of the adsorption of water vapor with that of nitrogen showed a decrease in adsorption until $250^{\circ} \mathrm{C}$, caused by a reduction in the number of hydroxyl groups. At above $250^{\circ} \mathrm{C}$, the adsorption increases as a result of the formation of capillaries in the wood due to gasification (Nakano. 2003). In the light of the above discussion by Nakano, the results plotted in Figure 3 are consistent with a decrease in adsorption sites and a lowering in hygroscopicity on heating for up to $5 \mathrm{hr}$, followed by an increase in capillaries upon the gasification or volatilization of bamboo after heating for more 5 $\mathrm{hr}$, which increases the hygroscopicity.

The hygroscopic behavior was evaluated in terms of the Hailwood and Horrobin theory used to describe the behavior of hydrophilic polymers. This theory has been applied successfully to wood and chemically modified wood. The theory assumes that the adsorbent is an ideal solid solution and invokes three constants: $K_{1}, K_{2}$, and $W . K_{1}$ and $K_{2}$ are equilibrium constants used to describe the interaction of dissolved water and the anhydrous polymer to form 
hydrous polymer, and the relationship between the dissolved water and the water vapor, respectively. $W$ is defined as the molecular weight of polymer substances per adsorption site. The relationships between $K_{1}, K_{2}, 1 / W$, and weight loss are shown in Figures 4 to 6 .

The relationships between the sample weight loss for a given heating time and the parameters $K_{1} K_{2}$ and $1 / W$ are shown in Figure 4 . The product $K_{1} K_{2}$ is the equilibrium constant for the reaction of water vapor with heated bamboo to form hydrous bamboo via monolayer adsorption. Figure 4 shows that $K_{1} K_{2}$ increases up to the heating time of 2 to $5 \mathrm{hr}$, after which it decreases linearly with further heating. This implies that adsorption ability peaks at 2 to $5 \mathrm{hr}$ and decreases thereafter, implying that the area of the internal surface is reduced on heating beyond 2 to $5 \mathrm{hr}$.

Figure 5 shows that the variation in $1 / W$ with weight loss is opposite of that for $K_{1} K_{2}$. That is, the number of sorption sites per mass $1 / W$ shows the minimum after heating for 2 to 5 $\mathrm{hr}$, but increasing linearly over the same time.

The relationships between $K_{1} K_{2}$ and $1 / W$ and the heating time are shown in Figure 5 .

Hailwood and Horrobin theory gives $K_{1} K_{2}=C_{1}+C_{2} /(1 / W)$, where $C_{1}$ and $C_{2}$ are constant and $K_{1} K_{2}$ is inversely proportional to $1 / W$. However, the direction of the plot varies before and after 
2 to $5 \mathrm{hr}$. Clearly both the chemical composition and physical structure of the internal surface contribute to the water adsorption changes upon heating time.

Hailwood and Horrobin theory is based on the presence of a specific adsorption site.

Consequently, it is impossible to discuss those samples for which the condensation of water in capillaries dominates over adsorption at specific sites, although appropriate parameters can be derived. For example, $1 / W$, the number of adsorption sites per unit mass of bamboo, shows the most adsorption after heating for $360 \mathrm{hr}$ with a weight loss of over $60 \%$. At this point, those components in the bamboo contributing to water adsorption, especially hemicellulose, are decomposed, but there will have been an increase in capillaries as a result of a loss of the bamboo components. The increase in the number of adsorption sites and change in the equilibrium constants for adsorption imply that Hailwood and Horrobin theory can be used only for samples with short heating times.

Saturated adsorption, arising from capillary condensed water, can also be modeled using the empirical equation of Dubinin and Radushkevich, which is used to describe the adsorption of vapors on microporous carbons (Dubinin. 1960, 1965). The amount of adsorption is: 


$$
m=m_{0} \exp \left[-\left(\frac{\varepsilon}{E_{0}}\right)^{2}\right]
$$

where $m_{0}$ is the moisture content of capillary condensed water, $\varepsilon$ is Polanyi' $s$ adsorption

potential, and $E_{0}$ is a parameter related to the interaction energy. Here, $\varepsilon=\mathrm{R} T \ln [1 / h]$ ( $\mathrm{R}$ is the gas

constant, $\mathrm{T}$ is the absolute temperature, and $h$ is the relative humidity).

With microporous carbons, this equation is invalid over a wide pressure range (Rand.

1976). We applied Dubinin and Radushkevich equation to our adsorption data and also

confirmed that this theory is not useful for the full range of relative humidities, but applies at

lower relative humidities. Therefore, the linear plot of $(\mathrm{RT} \ln [1 / h])^{2} \mathrm{vs} . \ln (m)$ for the adsorption data obtained at lower relative humidities was extrapolated to obtain its slope, $\left(1 / E_{0}\right)^{2}$, and intercept, $\ln \left(m_{0}\right)$, allowing the characteristic adsorption energy $E_{0}$ and saturated adsorption $m_{0}$ to be derived. Note that the obtained values are reliable for low relative humidities and lower moisture contents only, and not over a wide pressure range, including the fiber saturation point.

The relationship between parameter $m_{0}$ or $E_{0}$ in the Dubinin and Radushkevich theory and the measured weight loss is shown in Figure 6 with $m_{0}$ peaking after heating for 2 to $5 \mathrm{hr}$ and increasing linearly over longer heating times. This behavior is similar to that of parameter 1/W in Hailwood and Horrobin theory, as shown in Figure 4. $m_{0}$ represents the moisture content when all of the capillaries are filled with water molecules. Like the results for $1 / \mathrm{W}$, 
those for $m_{0}$ imply that heating for 2 to $5 \mathrm{hr}$ leads to the formation of capillaries upon gasification or volatilization. Conversely, $E_{0}$ decreased after peaking with heating for 2 to $5 \mathrm{hr}$. This is the same trend shown by Hailwood and Horrobin's parameter $K_{1} K_{2}$, the equilibrium constant for the interaction between the adsorbate and adsorbent, i.e., the formation of hydrous bamboo. Considering weight loss, parameter $E_{0}$ describes not only the formation of capillaries but also the adsorption mechanism of the bamboo on heating for 2 to $5 \mathrm{hr}$.

As illustrated by Hailwood and Horrobin theory, Figure 7 shows how the adsorption capacity of heated bamboo varies with the heating time from 2 to $5 \mathrm{hr}$. In this regard, $m_{0}$ shows little variation for heating for 1 to $5 \mathrm{hr}$. Subsequently, the only interaction change that occurs upon further heating is between water molecules and bamboo substances. 


\section{References}

Abe I, Hitomi M, Ikuta N, Kera Y (1996a) Pore structural analysis of charcoals by mercury intrusion porosimetry. Tanso 172: 77-82

Abe I, Kawafune I, Kera Y (1996b) Properties of porous carbons prepared from the wood of Japanese cypress - effect of carbonization time at $900^{\circ} \mathrm{C}$. Tanso 171: 18-23

Abe I, Fukuhara T, Maruyama J, Tatsumoto H., Iwasaki S (2001a.) Preparation of carbonaceous adsorbents for removal of chloroform from drinking water Carbon 39: 1069-1073

Abe I., Fukuhara T, Maruyama J, Iwasaki S, Yasuda K, Nakagawa K, Iwata Y, Kominami H, Kera Y (2001b) Development of a high density carbonaceous adsorbent from compressed wood. Carbon 39: 1485-1490

Dubinin MM (1960) The potential theory of adsorption of gases and vapors for adsorptions with energetically nonuniform surfaces. Chem Rev. 60: 235-241

Dubinin MM (1965) Theory of the bulk saturation of microporous activated charcoals during adsorption of gases and vapors. Russian J Phys Chem. 39: 697-704

Fujiwara S, Sima K, Ciba K (2003a) Carbonization condition and gas adsorption characteristics of the bamboo charcoal. Bamboo J 20: 68-76 
Fujiwara S, Sima K, Ciba K (2003b) Fundamental Characteristic and Humidity Control Capacity of Bamboo Charcoal. Mokuzai-Gakkaishi 49: 333-341

Hailwood AJ, Horrobin S (1946) Absorption of Water by Polymers - Analysis in Terms of a

Simple Model Trans Faraday Soc 42B: 84-92

Nakano T (2003) Surface fractal dimensionality and hygroscopicity for heated wood.

Holzforschung 57: 289-294

Rand B (1976) On the Empirical Nature of the Dubinin - Radushkevich Equation of Adsorption. J Colloid Interface Sci 56: 337-346 


\section{Captions}

Fig. 1. Weight loss of mousouchiku bamboo with heating time at $200^{\circ} \mathrm{C}$.

Fig. 2. Isothermal curves of wood heated for various times.

Fig. 3. Relationship between the moisture content and weight loss with heating time.

Fig. 4. Variation in the Hailwood and Horrobin parameters $K_{1} K_{2}$ and $1 / W$ with weight loss.

Fig. 5. Relationship between the Hailwood and Horrobin parameters $K_{1} K_{2}$ and $1 / W$.

Fig. 6. Variation in the Dubinin and Radushkevich parameters $m_{0}$ and $E_{0}$ with weight loss.

Fig. 7. Relationship between the Dubinin and Radushkevich parameters $E_{0}$ and $m_{0}$. 


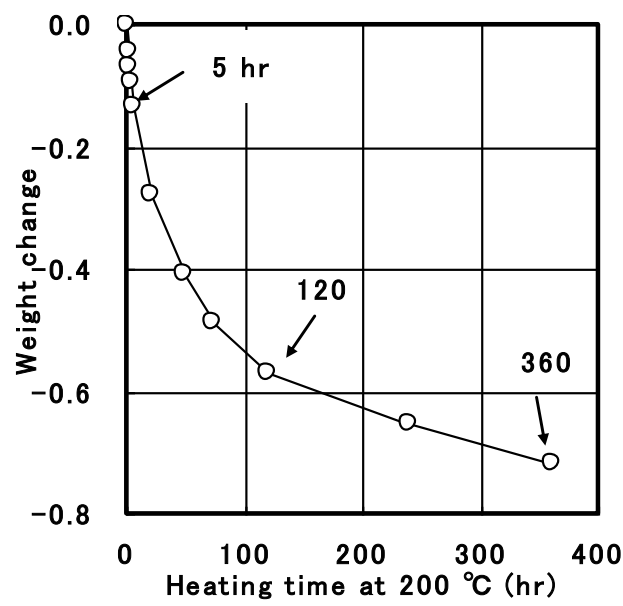

Fig. 1. Weight loss of mousouchiku bamboo with heating time at $200^{\circ} \mathrm{C}$. 


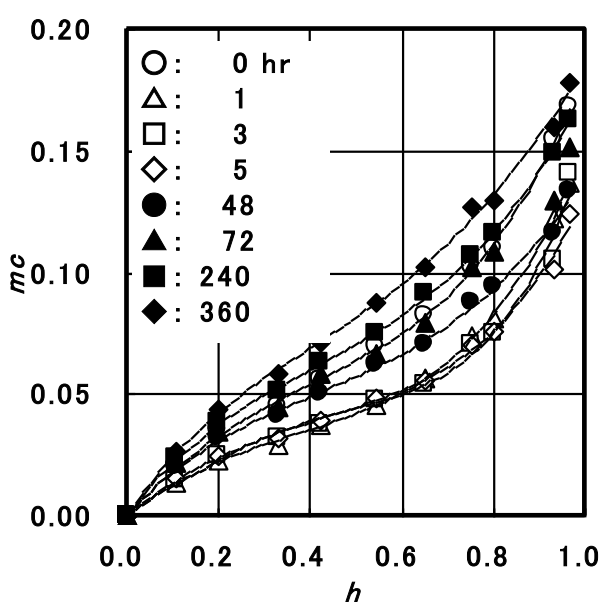

Fig. 2. Isothermal curves of wood heated for various times. 


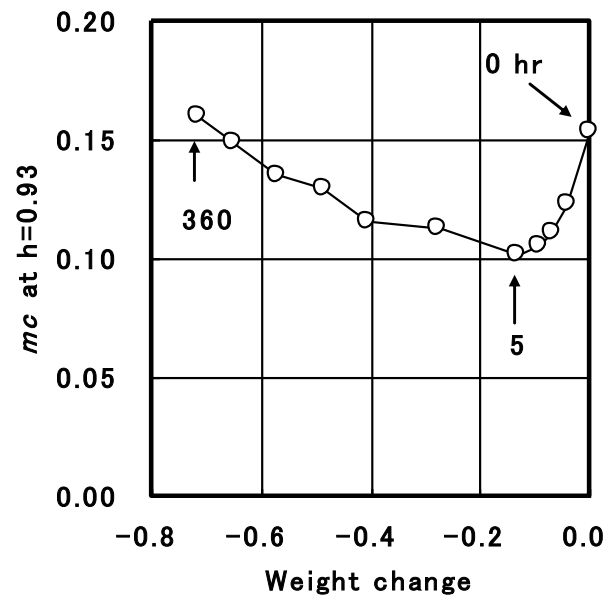

Fig. 3. Relationship between the moisture content and weight loss with heating time. 

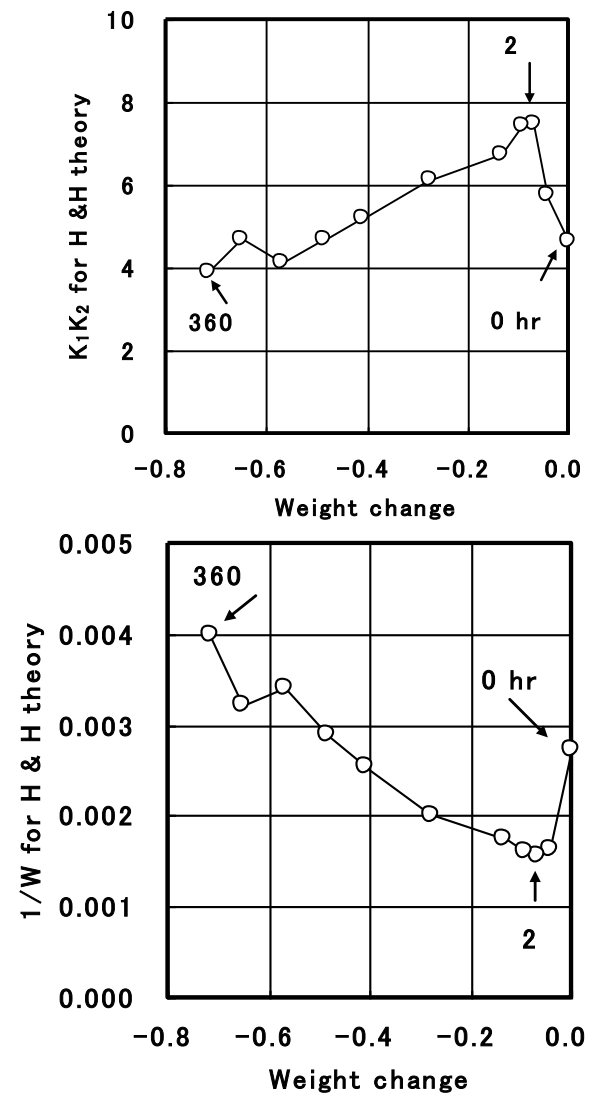

Fig. 4. Variation in the Hailwood and Horrobin parameters $K_{1} K_{2}$ and $1 / W$ with weight loss. 


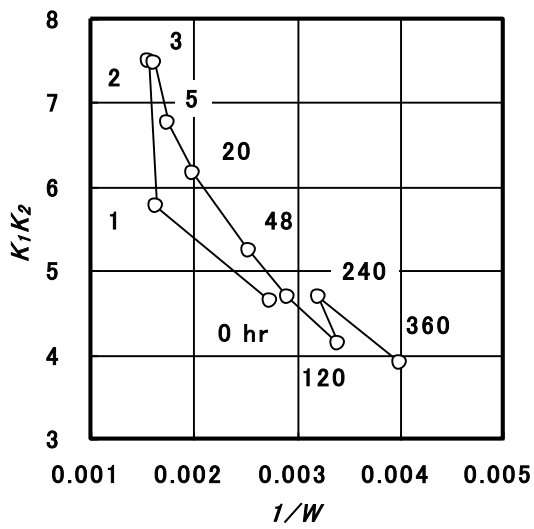

Fig. 5. Relationship between the Hailwood and Horrobin parameters $K_{1} K_{2}$ and $1 / W$. 

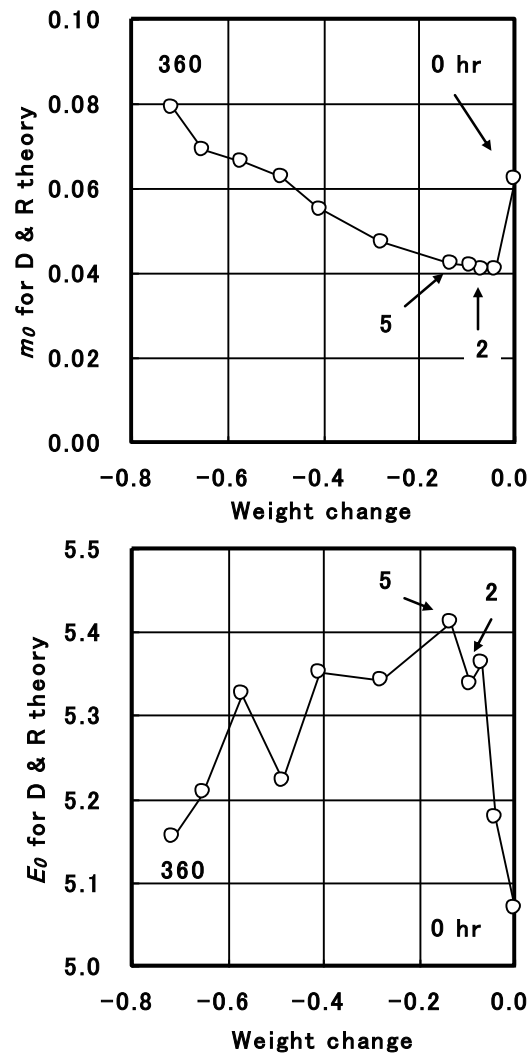

Fig. 6. Variation in the Dubinin and Radushkevich parameters $m_{0}$ and $E_{0}$ with weight loss. 


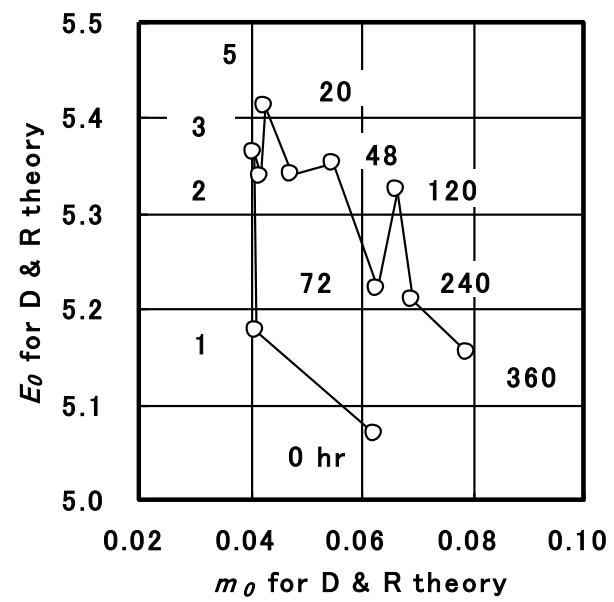

Fig. 7. Relationship between the Dubinin and Radushkevich parameters $E_{0}$ and $m_{0}$. 